\title{
PREDICTIVE VALUES OF BREAST IMAGING REPORTING AND DATA SYSTEM CATEGORY 3 BREAST MASSES SUBMITTED TO PERCUTANEOUS BIOPSY BY ULTRASONOGRAPHY
}

Valores preditivos dos nódulos mamários categoria 3 pelo sistema de laudos e registro de dados de imagem da mama submetidos à biópsia percutânea por ultrassonografia

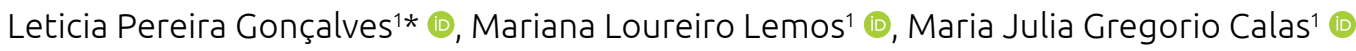

\section{ABSTRACT}

Introduction: Breast Imaging Reporting and Data System (BI-RADS) classification allows standardization of breast masses findings, with a recommendation for individualized management. Because of their high frequency, masses classified as 3, probably benign, arouse interest in improving their characterization and in establishing the most appropriate behavior. Objective: Firstly, to demonstrate the positive and negative predictive values of the BI-RADS 3 classification of solid masses submitted to percutaneous biopsy by ultrasonography. Secondly, to suggest a different ultrasound follow-up conduct in these findings. Methods: We retrospectively studied 480 BI-RADS 3 masses, submitted to a biopsy under vacuum or core biopsy, with a conclusive histopathological result considered the gold standard. Results: From 480 masses in 396 patients, 473 were benign and 7 malignant. The positive predictive value for malignancy of category 3 masses was 1.5\% (7/480), and the negative predictive value was $98.5 \%$. Conclusion: In view of the low probability of cancer, it is recommended the performance of directed ultrasonography (second look) of masses classified as BI-RADS 3 performed by a specialist in breast radiology before the indication of an invasive procedure, what would substantially reduce the number of unnecessary biopsies, patient's anxiety, as well as costs and possible related complications. This will increase the possibility for the specialist to spend more time on really necessary and targeted examinations, better defining cases of follow-up (annual or biannual) of the indication of investigation in specific cases.

KEYWORDS: breast neoplasms; diagnosis; biopsy; ultrasonography.

\section{RESUMO}

Introdução: A classificação do Breast Imaging Reporting and Data System (BI-RADS) permite a padronização dos achados das massas mamárias, com recomendação para o manejo individualizado. Por causa de sua alta frequência, massas classificadas como 3 , provavelmente benignas, despertam interesse em melhorar sua caracterização e em estabelecer o comportamento mais adequado. Objetivo: Primeiramente, demonstrar os valores preditivos positivos e negativos da classificação de massas sólidas BI-RADS 3 submetidos a biópsia percutânea por ultrassonografia. Em segundo lugar, sugerir conduta de acompanhamento por ultrassonografia diferente nesses achados. Metodologia: Estudamos, retrospectivamente, 480 massas BI-RADS 3, submetidas a biópsia a vácuo ou corebiopsia, com resultado histopatológico conclusivo considerado padrão-ouro. Resultados: De 480 massas em 396 pacientes, 473 eram benignas e 7 malignas. O valor preditivo positivo para malignidade de categoria 3 foi de 1,5\% (7/480) e o valor preditivo negativo foi de 98,5\%. Conclusão: Em vista da baixa probabilidade de câncer, recomenda-se a realização de ultrassonografia direcionada (second look) de massas classificadas como BI-RADS 3 por especialista em radiologia da mama antes da indicação de um procedimento invasivo, o que reduziria substancialmente o número de biópsias desnecessárias, ansiedade do paciente, bem como possíveis complicações. Isso aumentará a possibilidade de o especialista passar mais tempo em exames realmente necessários e direcionados, definindo melhor os casos de acompanhamento (anual ou semestral) da indicação da investigação em casos específicos.

PALAVRAS-CHAVE: neoplasias de mama; diagnóstico; biópsia; ultrassonografia.

${ }^{1}$ Clínica de Diagnóstico por Imagem - Rio de Janeiro (RJ), Brazil.

*Corresponding author: Ipgoncalves@hotmail.com

Conflict of interests: nothing to declare.

Received on: 11/16/2018. Accepted on: 12/27/2018 


\section{INTRODUCTION}

The American College of Radiology, with other important institutions on United States, created Breast Imaging Reporting and Data System, known as BI-RADS ${ }^{\oplus}$, used to describe the findings of various breast imaging modalities, including mammography, ultrasound and magnetic resonance imaging. It is also used to indicate a conduct for each case, with the aim of homogenizing the terms and reports, and facilitating the communication between the various professionals involved, as well as to better monitor and audit results ${ }^{1-3}$.

Breast ultrasound (US) has become a well-established imaging tool for breast cancer diagnosis. It is mainly due to the recent evolution of the equipment, allowing the identification of a greater number of hidden masses on mammography (27\%) - especially in women aged less than 50 years and with dense breasts -, as well as the distinction between benign and malignant masses, increasing the specificity of mammography when used as a complementary exam ${ }^{4-6}$.

However, despite the enhancement of BI-RADS-US in the most recent edition of 2013, and the numerous publications available, category 3 for masses observed by ultrasonography screening remains a major challenge to breast radiologists ${ }^{1}$.

The first purpose of this study is to present the positive predictive value (PPV) and negative predictive value (NPV) of masses classified as category 3 BI-RADS-US, submitted an ultrasound percutaneous biopsy at a private clinic in the city of Rio de Janeiro, Brazil. The second is to recommend a conduct of ultrasonography follow-up of these findings, knowing that the misinterpretation of the obtained image results entails many negative implications, among which unnecessary biopsies, patient's and attending physician's anxiety, and costly excessive complementary examinations, so that the diagnostic investigation can be continued ${ }^{4}$.

\section{METHODS}

A retrospective study was carried out on 396 patients, with 480 masses classified as BI-RADS-US category 3 on screening or diagnostic ultrasound, submitted to a percutaneous biopsy at a clinic dedicated to breast radiology in the city of Rio de Janeiro, Rio de Janeiro, Brazil.

The equipment used to perform the procedures was Logic P6 (GE Medical System Inc.) with a multi-frequency linear probe (7.5-12 MHz). The procedures performed, following the procedure described in the literature, by requested of the attending physician, were core biopsy or vacuum biopsy. The core biopsies were performed with BARD pistol with a range of 2.2 or $1.5 \mathrm{~cm}$, according to the depth and size of the lesion, and with a 14 Gauge needle. Vacuum biopsies were performed with Atec probe (Surtec Atec Sapphire, Hologic Inc.) with a 12 Gauge needle.

The 5 radiologists who classified the masses at the time of procedure and performed the biopsies are experienced physicians (ranging from 10 to 25 years) in breast image and interventional radiology.
The material considered satisfactory and conclusive was evaluated by a pathologist specializing in breast disease, with 20 years of experience in percutaneous procedures.

A solid mass with a circumscribed margin, oval shape, and parallel orientation, with no posterior features or minimal posterior acoustic enhancement on US, was categorized as BI-RADS $3^{1}$.

These cases come from a private service, and the patients are already referred to the procedures according to their requesting physician, without data on family risk and changes in physical examination. Due the biopsies are guided by ultrasound, there was no comparison with possible mammography findings. There is no information regarding whether these masses were palpable or not.

The Research Ethics Committee approved the project, and informed consent form was applied and signed by all patients, alongside verbal explanation of procedure and possible complications and care instructions after the biopsy.

The retrospective data were obtained from clinical database, through an image capture system in digital file and electronic form (e-form).

For data management, a new database of these patients was created using Microsoft Excel 2000 software, following the data management methodology usually used in research protocols.

The tests used in order to prove the proposed objective were the calculation of the PPV and the NPV of the biopsies of BI-RADS-US 3 masses.

The predictive values evaluate the likelihood of a disease (breast cancer), given the results of a diagnostic test. They are determined not only by the sensitivity and specificity of the test but also by the prevalence of the disease in the specific population. PPV is the proportion of true positives among all individuals with positive test, and NPV is the proportion of true negative among individuals with negative test. Statistical analysis was exploratory, comparative and performed using the Statistical Package for Social Sciences (SPSS), version 20.0 (Chicago, IL, USA). Categorical variables will be presented as absolute frequencies and percentages.

The characteristics evaluated were the specialty of the professional who requested the biopsy, the type of procedure performed (core or vacuum biopsy) and the age of patients. Regarding the lesions, the size of the masses was evaluated, being divided in $\leq 1$ and $>1 \mathrm{~cm}$, and the satisfactory histopathological result was considered gold standard.

The results of the exams and procedures performed were informed to the patients and their respective requesting physicians. These professionals would use the information received and decide upon treatment independently of this study, that is, either continue with adequate treatment in carcinoma cases or keep patient in follow-up in benign cases. The data obtained are confidential, and the photographic records of the images were used in this work. The nominal identification in the photo was erased, so that anonymity was maintained. 


\section{RESULTS}

Of the total number of biopsy requests, 320 were performed by breast surgeons, 130 by gynecologists and 30 by doctors with other specialties, among which 17 oncologists, 9 plastic surgeon, 2 geriatricians, 1 dermatologist and 1 proctologist. Regarding the results of malignant masses, all had their biopsy requested by breast surgeons.

Of 480 masses identified in 396 female patients, classified as BI-RADS 3 on breast ultrasound, submitted to percutaneous biopsy, 389 cases were core biopsy and 91 were vacuum biopsy, with 473 benign and 7 malignant results. Among the malignant lesions, 3 underwent vacuum biopsy and 4 core biopsy.

Patients' ages varied between 15 and 89 years, with a mean of 43 years. The mean patient age with malignant lesions was 54.7 years (ranging from 42 to 66 years) and with benign lesions was 49.4 years (ranging from 28 to 62 years).

As for masses size, the largest mean was $5.6 \mathrm{~cm}$ in the largest diameter and the smallest $0.5 \mathrm{~cm}$. The lesions were smaller than or equal to $1.0 \mathrm{~cm}$ in 250 cases (52\%) and larger than $1.0 \mathrm{~cm}$ in 230 cases (48\%). Malignant lesions averaged $1.45 \mathrm{~cm}$, ranging from 0.88 to $2.62 \mathrm{~cm}$.

Among the benign masses, the most common diagnosis was fibroadenoma; among the malignant, infiltrating ductal carcinoma was the most frequent finding.

The PPV for malignancy of category 3 masses in our study was $1.5 \%$ (7/480), and the NPV was $98.5 \%$ (473/480).

Table 1 presents the histopathological results of all percutaneous procedures, that were grouped in benign and malignant results. The benign ones were grouped into characteristic findings of proliferative and non-proliferative lesions, for a more objective presentation of the table presented.

Figures 1 to 4 show cases of this study, classified as BI-RADS 3 before percutaneous biopsy, being: 2 malignant cases (Figures 1 and 2) and 2 benign cases (Figures 3 and 4).

\section{DISCUSSION}

As ultrasound techniques continue to improve with higher-frequency linear transducers that increase spatial resolution, spatial compounding to improve margin analysis, tissue harmonic imaging that reduces near-field artifacts and intensifies posterior acoustic features, and more robust power Doppler, radiologists have the opportunity to increase their diagnostic confidence. This may lead to further refinements of BI-RADS 3 ultrasound criteria. With the increasing use of breast US screening in women with dense breasts, category 3 lesions are being found more often ${ }^{6-8}$.

BI-RADS 3 in breast imaging is an evolving category. When used properly, the purpose of the short-term follow-up algorithm is to reduces the number of benign biopsies (reduce false-positive exams) while allowing the breast imager to maintain a high sensitivity for the detection of early stage breast cancer ${ }^{2,9}$.

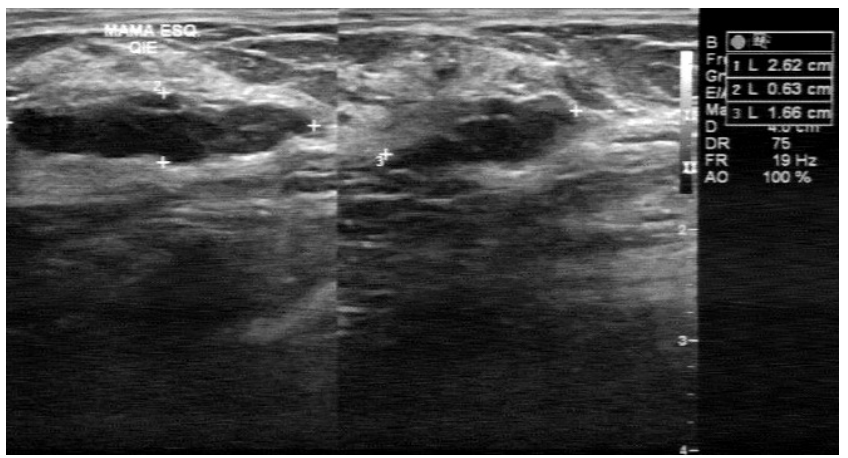

Figure 1. Hypoechoic, oval and circumscribed, parallel mass, without posterior features, measuring $2.6 \mathrm{~cm}$. Histopathologic result: Intracystic papillary carcinoma.

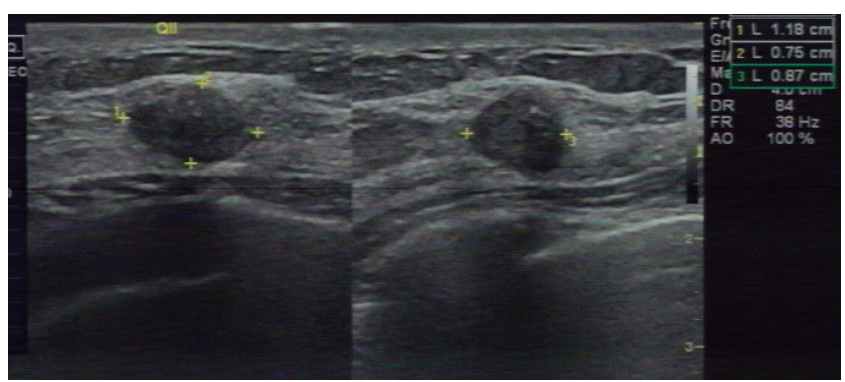

Figure 2. Hypoechoic, oval and circumscribed, parallel mass, with no posterior features, measuring $1.2 \mathrm{~cm}$. Histopathologic result: invasive tubular carcinoma.

Table 1. Histopathological results of 480 masses submitted to percutaneous biopsy, classified as Breast Imaging Reporting and Data System (BI-RADS) 3.

\begin{tabular}{|c|c|c|c|c|c|}
\hline Histopathological & $\begin{array}{l}\text { Absolute } \\
\text { number }\end{array}$ & $\begin{array}{c}\text { Percentage } \\
(\%)\end{array}$ & Result & C & V \\
\hline Fibroepithelial neoplasms a & 347 & 72.3 & Benign & 287 & 60 \\
\hline Non-proliferative injures ${ }^{b}$ & 97 & 20.2 & Benign & 82 & 15 \\
\hline Proliferative lesions without atypiac & 29 & 6.0 & Benign & 17 & 12 \\
\hline Invasive ductal carcinoma (non-special type) & 6 & 1.2 & Malignant & 3 & 3 \\
\hline Intracystic papillary carcinoma & 1 & 0.2 & Malignant & 0 & 1 \\
\hline
\end{tabular}

${ }^{a}$ Fibroepithelial neoplasms: fibroadenomas; ${ }^{b}$ non-proliferative lesions: fibrosis, cyst, pseudoangiomatous change, adipose inclusion, hamartoma, sclero-hyalinosis, lymphocytic infiltration; 'Proliferative lesions without atypia: alteration of columnar cells without atypia, adenosis, typical ductal hyperplasia, papillary apocrine hyperplasia without atypia, tubule-papillary adenoma, intracystic papilloma; C: core biopsy; V: vaccum biopsy. 
BI-RADS 3 creates a wide variety of actions and reactions. It causes patient anxiety, eliminates some unneeded biopsies, and often ignored by patients and referring clinicians. Radiologists who are not sure about what to do with a finding often overuse BI-RADS 3. There are three principles for the use or not of BI-RADS 3:

1. if the lesion is indeterminate or has worrisome features it is not BI-RADS 3;

2. BI-RADS 3 should not be used to delay diagnosis of a malignant appearing finding;

3. BI-RADS 3 should only be used after a full diagnostic workup ${ }^{2,10-12}$.

In Lee's article ${ }^{2}$, the authors cited Chae et al. results, that demonstrated the radiologist's difficulty using BI-RADS 3 for breast ultrasound. In their experience, $14.6 \%$ of screening ultrasounds were read as BI-RADS 3 . When, however, they reinterpreted the ultrasound exams using ACRIN 6666 criteria, 19.3\% of cases had an assessment change. Of 225 patients who had a BI-RADS change, 213 were changed to BI-RADS 2 and 12 were upgraded to BI-RADS-4. Chae et al. also found that the malignancy rate was higher for those with abnormal mammograms compared with those who had normal mammograms (2.2 vs. $0.4 \%)$. This suggests an avenue for future research $\mathrm{h}^{3,13,14}$

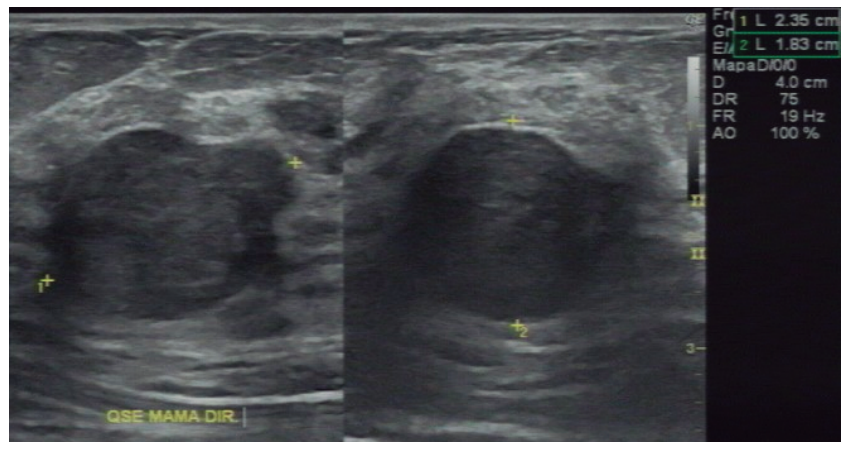

Figure 3. Hypoechoic, circumscribed, oval, parallel mass, with minimal posterior acoustic enhancement, measuring $2.4 \mathrm{~cm}$. Histopathological result: fibroadenoma.

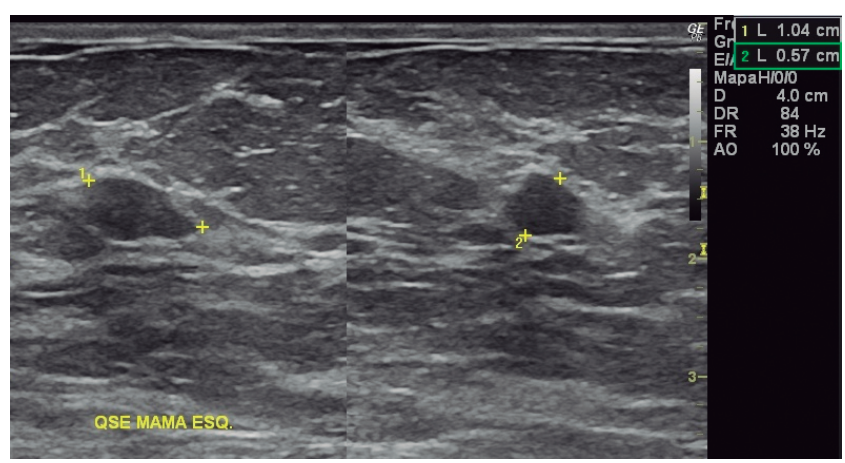

Figure 4. Hypoechoic, circumscribed, oval, parallel mass, with no posterior features, measuring $1.0 \mathrm{~cm}$. Histopathological result: fibroadenoma.
Interobserver concordance studies in breast ultrasound have Kappa indexes ranging from 0.28 (poor) to 0.83 (substantial) in the literature. This variation is very broad based on a subjective characterization of the images by the radiologist, depending on his experience ${ }^{7,15}$. According to Calas et $a .^{6}{ }^{6}$, the main difference features between a benign and a malignant mass are the contour and shape, the contour with the highest sensitivity and the shape the highest specificity.

BI-RADS describes a solid mass with circumscribed margin, oval shape and parallel orientation to the skin, with a probability of malignancy of up to $2 \%$, within the defined range of probable benignity ${ }^{1,2,4,7-14}$.

BI-RADS category 3 is not an indeterminate category and should not be used in case of doubt by the radiologist for benign or suspected lesions (BI-RADS 2 and 4, respectively). It is reserved for specific cases with a chance of malignancy between 0 and $2 \%^{1,2,15-17}$.

The incidence of BI-RADS 3 lesions on US has been reported between 15.7 and $32.2 \%$, and the malignancy rate between 0 and $2.6 \%{ }^{16-18}$. Due to their high frequency and low probability of cancer, by both ultrasound screening and diagnosis, these nodules arouse in the professionals dedicated to breast radiology a great interest in improving their characterization and in establishing the most appropriate conduct $\mathrm{t}^{7-14,18-24}$.

In the conduct for category 3 , the initial follow-up interval is usually six months, regarding the breast with the probable benign finding, with the recommendation of a second short-term follow-up of six months of the breasts bilaterally (12 months of the initial study), assuming stability in the test ${ }^{1-3,5}$. After that, due to the stability of the 12 months already observed, the recommended follow-up is of 1 year. As in the follow-up of screening mammography, after 2 to 3 years of stability, the final evaluation category should be changed to benign (category BI-RADS 2) ${ }^{25-30}$.

Our study showed a PPV for malignancy of $1.5 \%$ and NPV of $98.5 \%$.

Of the requests for biopsies performed, $66.6 \%$ were requested by breast surgeons, being the 7 cases of malignancy requested by them. Of all lesions, $56.4 \%$ were smaller than or equal to $1.0 \mathrm{~cm}$, and $43.6 \%$ were larger than $1.0 \mathrm{~cm}$, which could justify the indication of the biopsy of these masses, because they are larger than $1.0 \mathrm{~cm}$ and probably palpable.

In some studies ${ }^{20,21}$, the factors related to biopsies in category 3 masses were patients' preference (patient's wishes), patients' risk factors, suspicious changes in the follow-up interval (increase in volume and/or changes in lesion morphology) and investigator's doubts.

In our study, in addition to limiting the access to information regarding the need for biopsy, we can also cite: the access to the previous examinations (to evaluate image stability), the family or personal history of breast cancer, the lack of correlation with the mammographic findings, and, finally, information about the follow-up of these images with benign histopathology. 
Badan $^{24}$ and Raza et al. ${ }^{25}$ reported a PPV of 0 and of $0.8 \%$, respectively, for malignancy for category 3 masses. They concluded that a conservative management of BI-RADS category 3 lesions on screening breast ultrasound would be adequate in order to avoid unnecessary biopsies.

In the study of Berg et al. ${ }^{17}$, with 127 masses in asymptomatic patients, with heterogeneously dense breasts and at least 1 risk factor for breast cancer, there was no case of malignancy over a 2-year follow-up. With the use of correctly ultrasonography features of each mass, these authors recommended 1-year followup for circumscribed and benign masses by US.

Barr et al. ${ }^{20}$ presented results and similar follow-up proposals. They reported a $0.9 \%$ cancer rate in category 3 lesions in women at increased risk of breast cancer. Only one case presented suspicious modifications at the 6-month follow-up and another at the 1-year follow-up, both infiltrating ductal carcinomas, with negative axillary lymph nodes. Thus, it is recommended an annual follow-up of the BI-RADS lesions 3.

Some studies have related the findings as the findings are palpable or not. Park et al..$^{22}$ found a PPV of $0.6 \%$ (1 case of infiltrating ductal carcinoma grade 2 and 1 case of mucinous carcinoma, axillary negative lymph nodes) and $99.4 \%$ NPV, with no difference between palpable and impalpable masses. In the study by Barr et al..$^{20}$, a rate of $19.5 \%$ of category 3 lesions was observed on screening ultrasonography in women at increased risk of breast cancer and with dense breasts, with a malignancy rate of $0.8 \%$, all impalpable lesions.

Graf et al. ${ }^{16}$, with 448 masses, showed no malignant lesions, either on screening exams or at follow-up over a period of two years; the palpable lesions with benign morphology on the image might be similarly accompanied as non-palpable lesions.

Kapsimalakou et al. ${ }^{12}$ concluded that it is critical that the attending physician be able to rely on the radiologist's ability to distinguish probably benign lesions from lesions that should be readily biopsied. Image follow-up would identify the progression of malignant lesions, but most cancers will continue to be diagnosed early, resulting in a favorable prognosis, a finding corroborated by Sickles ${ }^{13}$. They also include positive factors such as increased PPV of biopsies, reduction of morbidity associated with percutaneous or surgical biopsy, and reduction of costs.

Alimoglu et al. ${ }^{4}$ found a $5.3 \%$ frequency of category 3 nonpalpable masses in non-risk patients. Seventy percent of them remained stable for two years. The malignancy rate was $0.3 \%$, and $85 \%$ of the changes occurred in the first two years of follow-up, namely, progression in size greater than $20 \%$ and morphological change. These authors also showed a $60 \%$ reduction in costs with follow-up compared to biopsy, with the advantage of lower morbidity, lower risk and fewer complications.

Stavros et al. ${ }^{19}$ concluded that, although invasive procedures are well tolerated, they present some hindrances, such as discomfort and patient anxiety, increased costs, which include recovery time and total health costs.

Another interesting point is that even BI-RADS 3 lesions that had the histopathological diagnosis established should continue the follow-up for two or three years for complete safety in stability, and, therefore, benignity. This fact makes follow-up even more cost-effective and not immediate biopsy'.

Briefly, there is a high incidence of BI-RADS 3 masses on US alongside a low incidence of cancer, inducing thereby to unnecessary control tests, as well as invasive procedures. However, several factors should be considered when determining the conduct of patients with category 3 BI-RADS masses. For example, cost evaluation (cost of a possible biopsy, percutaneous or surgical, emotional exhaustion, operational costs, unnecessary repetition of exams), especially in countries like Brazil, where the majority of the population uses public health services that are often precarious ${ }^{14}$.

Another still controversial point of interest would be the best interval for follow-up examinations of such masses and how this examination would be performed, i.e., in a targeted fashion, unilateral, or bilateral and complete.

Prior to the biopsy request of a mass previously classified like BI-RADS 3, and in some cases BI-RADS 4A, the ultrasound performed in a targeted fashion to the image in question by an experienced professional in breast radiology, compared with previous exams and other imaging tests, could reduce the indication for biopsy and increase their PPV. This would result in reduction in both morbidity and patient's cost.

Short-term follow-up could hence be performed with greater safety, what would bring greater comfort for the attending physician to give up on the histopathological diagnosis, since ultrasonographic criteria for nodule classification are to be adequately applied by experienced breast radiologists. The images could be reclassified as BI-RADS 2 and be kept under annual control, or classification BI-RADS 3 could be maintained with a new directed study in 6 months or yet an indication for biopsy in the event of reclassifying the image as BI-RADS 4.

\section{CONCLUSION}

Ultrasound is readily available, uses no ionizing radiation, and is well tolerated by patients. In women with dense breasts tissue, supplemental breast ultrasound imaging can increase cancer detection rates by 1.8 to 4.6 per $1,000^{20}$. However, in finding more cancers, supplemental ultrasound will also discover more benign masses that are not characteristically benign in appearance, increasing the number of biopsies and false-positive rates. Breast masses BI-RADS 3, probably benign, is a challenging assessment category.

From NPV results of $98.5 \%$ in our study, we recommend that a dedicated breast radiologist perform a US-directed 
BI-RADS category 3 mass prior to the indication for a possible intervention. This would reduce substantially the number of unnecessary biopsies, as well as the costs and complications related to it. Moreover, this would give more confidence to the assistant physician to characterize correctly lesions and to suggest an annual follow-up. However, a large series prospective study is needed before further studies validate this recommendation.

\section{REFERENCES}

1. Mendelson EB, Böhm-Vélez M, Berg WA, Whitman GJ, Feldman MI, Madjar H, et al. ACR BI-RADS ultrasound. In: D’Orsi CJ, Sickles EA, Mendelson EB, Morris EA, editors. ACR BI-RADS Atlas: Breast Imaging Reporting and Data System. Reston: American College of Radiology; 2013.

2. Lee KA, Talati N, Oudsema R, Steinberger S, Margolies LR. BI-RADS 3: Current and Future Use of Probably Benign. Curr Radiol Rep. 2018;6(2):5. https://doi.org/10.1007/ s40134-018-0266-8

3. Jang JY, Kim SM, Kim JH, Jang MJ, Yun BL, Lee JY, et al. Clinical significance of interval changes in breast lesions initially categorized as probably benign on breast ultrasound. Medicine. 2017;96(12):e6415. https://doi.org/10.1097/ MD.0000000000006415

4. Alimoglu E, Bayraktar SD, Bozkurt S, Çeken K, Kabaalioglu A, Apaydin A, et al. Follow-up versus tissue diagnosis in BI-RADS category 3 solid breast lesions at US: a cost-consequence analysis. Diagn Interv Radiol. 2012;18(1):3-10. https://doi. org/10.4261/1305-3825.DIR.4462-11.1

5. Kim SY, Han BK, Kim EK, Choi WJ, Choi Y, Kim HH, et al. Breast Cancer Detected at Screening US: Survival Rates and Clinical-Pathologic and Imaging factors Associated with Recurrence. Radiology. 2017;284(2):354-64. https://doi. org/10.1148/radiol.2017162348

6. Calas MJG, Koch HA, Dutra MVP. Ultra-sonografia mamária: avaliação dos critérios ecográficos na diferenciação das lesões mamárias. Radiol Bras. 2007;40(1):1-7. http://dx.doi. org/10.1590/S0100-39842007000100003

7. Calas MJG, Almeida RMVR, Gutfilen B, Pereira WCA. Interobserver concordance in the BI-RADS classification of breast ultrasound exams. Clinics. 2012;67(2):185-9. https:// dx.doi.org/10.6061\%2Fclinics\%2F2012(02)16

8. Lee S, Jung Y, Bae Y. Synchronous BI-RADS Category 3 Lesions on Preoperative Ultrasonography in Patients with Breast Cancer: Is Short-Term Follow-Up Appropriate? J Breast Cancer. 2015;18(2):181-6. https://doi.org/10.4048/jbc.2015.18.2.181

9. Borders MH, Cheng L, Fitzpatrick KA, Krupinski EA. Patient Compliance in the Setting of BI-RADS Category 3: What Factors Impact Compliance With Short-Term Follow-Up Recommendations? Breast J. 2016;23(1):77-82. https://doi. org/10.1111/tbj.12687

10. Gruber R, Jaromi S, Rudas M, Pfari G, Riedl CC, Flöry D, et al. Histologic work-up of non-palpable breast lesions classified as probably benign at initial mammography and/or ultrasound (BI-RADS category 3). Eur J Radiol. 2013;82(3):398-403. https:// doi.org/10.1016/j.ejrad.2012.02.004
11. Moon HJ, Kim MJ, Yoon JH, Kim EK. Follow-up interval for probably benign beast lesion on screening ultrasound in women at average risk for breast cancer with dense breasts. Acta Radiol. 2018;59(9):1045-50. https://doi. org/10.1177/0284185117745906

12. Kapsimalakou S, Waldmann A, Katalinic A, Grande-Nagel I, Fischer D, Barkhausen J, et al. Follow-up of probably benign lesions in non-screening breast diagnostics. Arch Gynecol Obstet. 2014;290(3):543-51. https://doi.org/10.1007/s00404014-3233-5

13. Sickles EA. Probably benign breast lesions: when should follow-up be recommended and what is the optimal follow-up protocol? Radiology. 1999;213(1):11-4. https://doi.org/10.1148/ radiology.213.1.r99oc4611

14. Chala L, Endo E, Kim S, Castro F, Moraes P, Cerri G, et al. Grayscale sonography of solid breast masses: diagnosis of probably benign masses and reduction of the number of biopsies. J Clin Ultrasound. 2007;35(1):9-19. https://doi.org/10.1002/jcu.20298

15. Elverici E, Zengin B, Barca AN, Yilmaz PD, Alimli A, Araz L. Interobserver and intraobserver agreement of sonographic BIRADS lexicon in the assessment of breast masses. Iran J Radiol. 2013;10(3):122-7. https://dx.doi. org/10.5812\%2Firanjradiol.10708

16. Graf O, Helbich TH, Hopf G, GrafC, Sickles EA. Probably benign breast masses at US: is follow-up an acceptable alternative to biopsy? Radiology. 2007;244(1):87-93. https://doi.org/10.1148/ radiol. 2441060258

17. Berg WA, Zhang Z, Cormack JB, Mendelson EB. Multiple Bilateral Circumscribed Masses at Screening Breast US: Consider Annual Follow-up. Radiology. 2013;268(3):673-83. https://doi.org/10.1148/radiol.13122251

18. Kim K, Song MK, Kim E-K, Yoon JH. Clinical application of S-Detect to breast masses on ultrasonography: a study evaluating the diagnostic performance and agreement with a dedicated breast radiologist. Ultrasonography. 2017;36(1):3-9. https://doi.org/10.14366/usg.16012

19. Stavros AT, Thickman D, Rapp CL, Dennis MA, Parker SH, Sisney GA. Solid breast nodules: use of sonography to distinguish between benign and malignant lesions. Radiology. 1995;196(1):123-34. https://doi.org/10.1148/ radiology.196.1.7784555

20. Barr RG, Zhang Z, Cormack JB, Mendelson EB, Berg WA. Probably benign lesions at screening breast US in a population with elevated risk: prevalence and rate of malignancy in the ACRIN 6666 trial. Radiology. 2013;269(3):701-12. https://doi. org/10.1148/radiol.13122829 
21. Nam SY,KoEY,Han B-K, Shin JH, Ko ES, Hahn SY.Breast Imaging Reporting and Data System Category 3 Lesions Detected on Whole-Breast Screening Ultrasound. J Breast Cancer. 2016;19(3):301-7. https://dx.doi.org/10.4048\%2Fjbc.2016.19.3.301

22. Park YM, Kim EK, LeeJH, Ryu JH, Han SS, Choi SJ, et al. Palpable breast masses with probablybenign morphology at sonography: can biopsy be deferred? Acta Radiol. 2008;49(10):1104-11. https://doi.org/10.1080/02841850802438504

23. Ha SM, Chae EY, Cha JH, Shin HJ, Choi WJ, Kim HH. Growing BI-RADS category 3 lesions on follow-up breast ultrasound: malignancy rates and worrisome features. Br J Radiol. 2018;91(1087):20170787. https://doi.org/10.1259/bjr.20170787

24. Badan GM, Roveda Júnior D, Ferreira CAP, Ferreira FAT, Fleury EFC, Campos MSCA, et al. Valores preditivos positivos das categorias 3, 4 e 5 do Breast Imaging Reporting and Data System (BI-RADS ${ }^{\circledR}$ ) em lesões mamárias submetidas a biópsia percutânea. Radiol Bras. 2013;46(4):209-13. http://dx.doi. org/10.1590/S0100-39842013000400006

25. Raza S, Chikarmane SA, Neilsen SS, Zorn LM, Birdwell RL. BIRADS 3, 4, and 5 lesions: value of US in management: followup and outcome. Radiology. 2008;248(3):773-81. https://doi. org/10.1148/radiol.2483071786
26. Abdullah N, Mesurolle B, El-Khoury M, Kao E. Breast Imaging Reporting and Data System Lexicon for US: Interobserver Agreement for Assessment of Breast Masses. Radiology. 2009;252(3):665-672. https://doi.org/10.1148/ radiol. 2523080670

27. Shin JH, Han BK, Ko EY, Choe YH, Nam SJ. Probably benign breast masses diagnosed by sonography: is there a difference in the cancer rate according to palpability? AJR Am J Roentgenol. 2009;192(4):W187-91. https://doi.org/10.2214/AJR.08.1404

28. Calas MJG, Almeida RMVR, B. Gutfilen B, Pereira WCA. Intraobserver interpretation of breast ultrasonography following the BI-RADS classification. Eur J Radiol. 2010;74(3):525-8. https://doi.org/10.1016/j.ejrad.2009.04.015

29. Kim SJ, Chang JM, Cho N, Chung SY, Han W, Moon WK. Outcome of breast lesions detected at screening ultrasonography. Eur J Radiol. 2012;81(11):3229-33. https://doi. org/10.1016/j.ejrad.2012.04.019

30. Ackermann S, Schoenenberger C-A, Zanetti-Dällenbach R. Clinical Data as an Adjunct to Ultrasound Reduces the FalseNegative Malignancy Rate in BI-RADS 3 Breast Lesions. Ultrasound International Open. 2016;2(3):E83-9. https:// dx.doi.org/10.1055\%2Fs-0042-110657 